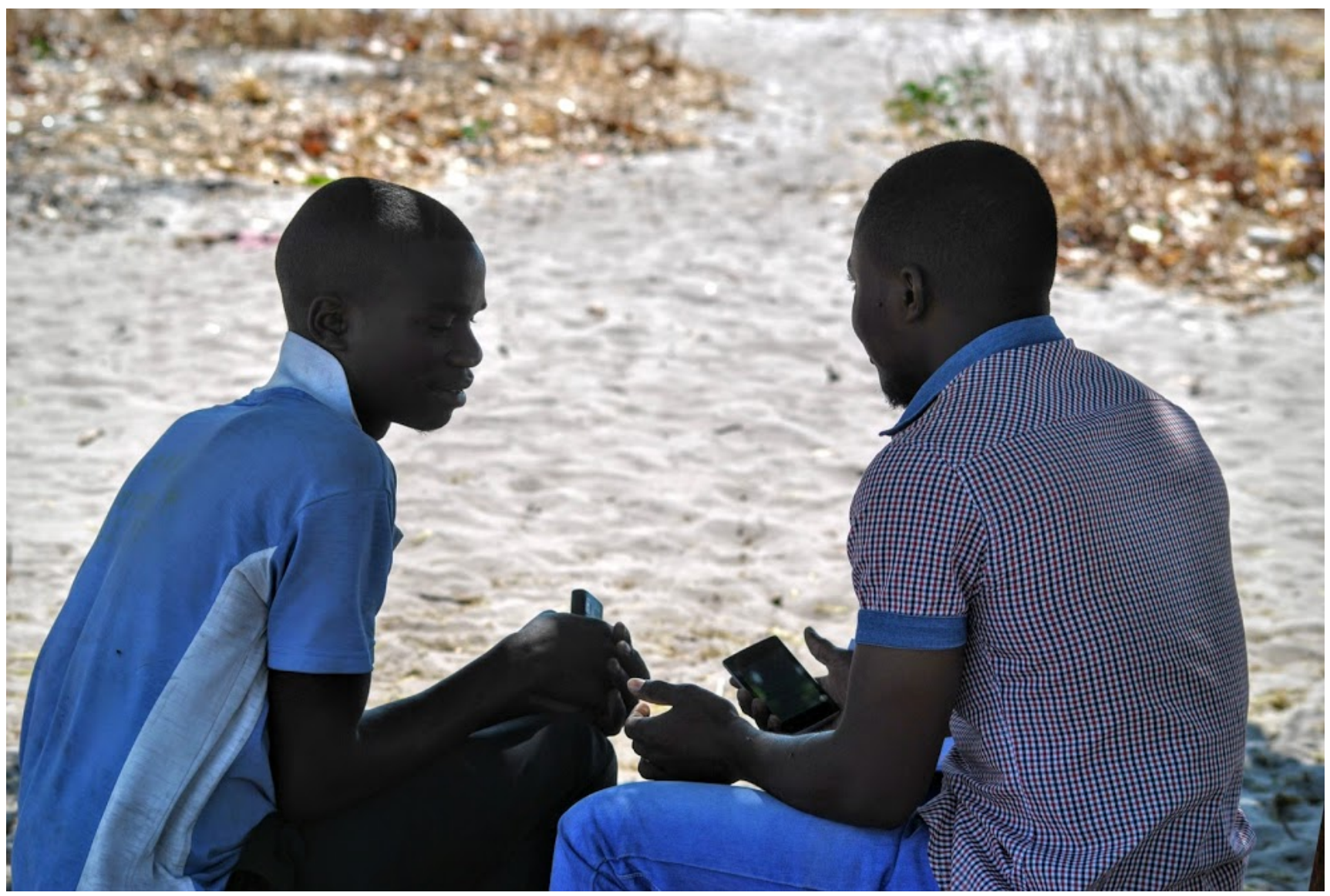

Data collection in Zambia. Photo: Bryan/Oxfam

\title{
GOING DIGITAL
}

\section{Improving data quality with digital data collection}

Three years on from the Going Digital: Using digital technology to conduct Oxfam's Effectiveness Reviews pilots, where we shared learning on the added value of using digital technology to conduct our impact evaluations, Oxfam continues to develop its survey techniques through the use of technology. The second paper in this series, Going Digital: Using and sharing real-time data during fieldwork, demonstrated how Oxfam was sharing realtime data during fieldwork to increase engagement and participation in surveyed communities, as well as improving integration between qualitative and quantitative data collection techniques. In this third paper, we present some of the features enabled by digital data collection technology that we have been piloted and used to improve quality and accuracy of data. It also explores ways in which the ethics of respecting privacy can be improved in survey data collection. 


\section{INTRODUCTION}

In 2015, Oxfam GB's team of Impact Evaluation Advisers started using digital devices to conduct household surveys for Oxfam's Effectiveness Reviews (internal quasi-experimental impact evaluations). In the last three years, we have conducted individual and household surveys using digital devices in more than 20 countries for the majority of our Effectiveness Reviews benefitting from improvements in data security, accountability, accuracy and timing, and even reducing costs.

We documented and shared our experience of making the transition from a paper process to a digital one in Going Digital: Using digital technology to conduct Oxfam's Effectiveness Reviews. We shared our experience in processing and sharing data in real time during fieldwork in Going Digital: Using and sharing real-time data during fieldwork. In this paper, we present some of the features used for improving the quality of data collected through household and individual surveys. In many of these data collection processes we took advantage of features provided by digital devices to pilot and implement solutions that would help to increase data quality. We recognize the limitations of automated technology, and there remains a need for expertise and rigour in monitoring and analysing data, but this paper explores the role that in-built functionality can offer to ensure data meets certain standards.

In this document, we will present some of the digital data collection features employed during survey data collection in the last three years and argue how these enable data-quality improvements to consistently meet or exceed sector standards. ${ }^{1}$ In the appendices, we will also provide practical examples with the accompanying code ${ }^{2}$ from SurveyCTO, a mobile data collection software application, and Stata, statistical analysis software. Through these examples, and by making the code available, we hope that other colleagues and practitioners will be able to build on our experience to use and extend digital data collection features, ultimately improving data quality and survey practices. We hope this technical and practical guide is useful for colleagues and practitioners implementing survey data collection with digital technologies. The sections of the paper are grouped by survey features that demonstrate the quality checks implemented and why, with a link to the appendix, which shows the associated coding used in SurveyCTO and Stata.

\section{PRE-RECORDED CONSENT FORM}

One area identified as critical in our experiences collecting data for monitoring and evaluation, is how informed consent is explained by the enumerator and obtained from the respondent. Oxfam's Responsible Program Data Policy defines informed consent as 'a process for getting willing permission to collect data of any kind based on a clear appreciation and understanding of the facts, implications, and consequences of any engagement from participants'. ${ }^{3}$ The Responsible Program Data Policy was released in 2015, framed according to the following rights: the right to be counted and heard; the right to dignity and respect; the right to make an informed decision; the right to privacy; and the right to not be put at risk. The right to make an informed decision includes the decision of the respondent as to whether they give informed consent to participate in the survey or any data collection exercise.

All data collection activities use a consent statement that is traditionally read out to, or read by, the respondent. Obtaining consent is more than following a standard template, it involves an open conversation, the ability to ask questions, and is very contextual. Oxfam is exploring ways in which it can improve the consent framework, which is outlined in a blog on 'Early stage prototyping: Consent 
and data minimisation for those affected by humanitarian crisis'. However, at the most basic level, there is a concern amongst researchers and monitoring and evaluation practitioners that during data collection processes, the consent statement is not always given enough attention by the enumerators at the beginning of the interview. During training, significant emphasis is put on obtaining consent appropriately, but it has still been found that at times this is cut short or missed altogether. The ICT in Programme team explore how the use of technology offers opportunities to amplify and improve the effectiveness of Oxfam's programme work and have looked at ways in which technology can improve how we explain and obtain informed consent from the respondent.

During a multi-country baseline, Oxfam recorded the consent statement in five different languages required for the survey. At the beginning of each interview the enumerators played an audio of the pre-recorded consent form, explaining the purpose of the survey. An example of this consent code is given in the appendix.

As a way to further ensure quality, the survey team was also able to check if the audio had been played fully before the beginning of the interview, as speed checks on the length of the audio files were introduced. When the time taken was less than the length of the audio recording in the local language, the data export would flag that the audio file had been cut short. This meant that supervisors could follow up with enumerators about playing the full audio file, leading to improvements and ensuring that respondents heard the whole consent form. This process was not without its challenges; some audio files had poor quality sound making it a challenge to hear, and supervisors were unable to find time to do thorough checks and follow up with enumerators when necessary. What the process demonstrated was that often the audio file was not played in full and only where supervisors followed up the speed violations with the enumerators did the process see a marked improvement.

In future data collection processes, it is advisable to combine pre-recorded consent forms with a written version of the consent form to be left with the respondent. This will ensure the respondent also has a written record, including the contact details, in case they decide to withdraw their consent.

\section{GENERATING UNIQUE IDENTIFIERS}

Unique identifiers, also known as IDs, are essential when data analysis requires the merging of different sources of information, such as questionnaires conducted with different respondents and at different levels (household and individuals, producer group and producer group members, etc.), or several data collection exercises scheduled with the same respondents. Depending on the type of sampling approach, IDs can be preloaded or generated on the spot. ${ }^{4}$ For Oxfam's Effectiveness Reviews, identifiers are used to link datasets together, and personal information is also collected to enable future data collection exercises as needs be. However, in some instances, identifiers can be used to minimize the personal data collected and stored, in which case randomization of a series of characters could be used to generate identifiers.

\section{PRELOADING IDENTIFIERS}

When it is possible to obtain the full lists of respondents before starting data collection, it is advisable to assign the ID to each respondent before beginning the survey. Preloading allows for information at 
hand (such as names and IDs) to be pre-entered in the survey. While preloading of identifier information is possible in a paper-based survey, the process and survey logistics are made more flexible when using digital technologies; it allows the uploading of the complete list of respondents on the devices, is accessible offline, and reduces the risk of mistakes in entering the identifiers.

Enumerators can simply filter by geographical area, and a list of contact details with the associated ID will show up for the enumerator to select. An example of the SurveyCTO code is presented in the appendix.

\section{IDENTIFIERS GENERATED ON THE SPOT}

In many instances, it is not possible to obtain the full list of sampled units in advance, such as households, making it then impossible to create a preloaded file with unique identifiers. In such cases, the survey team will have to create unique identifiers on the spot, once sampling is done, and assign the identifier consistently across the different survey tools (household and individual surveys in the setting of the Effectiveness Reviews for example). Typically, this creates challenges of duplication and consistency. One way to do this to avoid these mistakes is to combine a variety of information, such as geographical information, enumerator ID, interview date, and sampling order. When generating such ad-hoc identifiers, digital data collection helps by reducing the amount of information that is entered manually, thus decreasing the chances of mistakes. Examples of the SurveyCTO code are presented in the appendix. However, it is important to be aware that, while such a system reduces the chances of errors, it does not prevent them entirely - mistakes in information entered manually can still occur. This is why good tracking tools need to be put in place by the survey team, to ease information flow within the team. Daily monitoring as the data comes in is also key (see section 'Survey progress monitoring and automated quality checks' below).

Finally, under both scenarios (preloaded or ad-hoc identifiers), there is a trade-off between reducing the chances of mistakes by automating the generation of IDs and allowing the program to accommodate any unforeseen challenges (such as a village being inaccessible, an enumerator having to leave the team, sudden changes in the composition of teams, etc.). The SurveyCTO codes presented in the appendix allow for flexibility by including 'other' categories at every stage of the identification process (at different geographical area levels, household level, and enumerator identification), and enumerators are trained to use these 'other' categories as a last resort.

\section{HOUSEHOLD ROSTER INTERVIEW FLOW}

The household roster is an important component in most household surveys as it contains detailed information of all the household members involved in a survey. Accurately gathering this information is particularly important to ensure quality data to understand the make-up of a household and ensure no one is omitted. At the same time, because the questions are repeated for each individual, the process of collection can take a long time and be error prone.

While digital data collection provides an easier interview process compared with paper-based interviews, there is still a concern that, because of the number of follow-up questions for each household member, respondents might be tempted to avoid mentioning some household members to shorten the length of the survey. To obviate this issue and minimize such risk, Oxfam GB's Impact Evaluation Advisers were keen to ensure that the household roster section was set up with a specific 
workflow. This flow would require the enumerator asking first how many people lived in the household, followed by asking all their names, and finally following up with the specific questions about each household member.

Figure 1: Example household roster - paper survey form

\begin{tabular}{|c|c|c|c|c|c|c|c|c|c|c|}
\hline \multirow{2}{*}{ No } & \multirow{2}{*}{\begin{tabular}{|l|}
101 \\
Name of \\
household \\
member
\end{tabular}} & \multirow{2}{*}{\begin{tabular}{|l|}
102 \\
Identify the \\
person \\
interviewed
\end{tabular}} & \multirow{2}{*}{\begin{tabular}{|l|}
103 \\
Identify the \\
head of \\
household.
\end{tabular}} & \multicolumn{2}{|l|}{104} & \multirow{2}{*}{\begin{tabular}{|l|}
105 \\
What is \\
his/her \\
age? \\
Enter the \\
approximat \\
e age in \\
years.
\end{tabular}} & \begin{tabular}{|l|}
106 \\
What is \\
his/her marital \\
status?
\end{tabular} & $\begin{array}{l}107 \\
\text { What is the } \\
\text { highest level of } \\
\text { education } \\
\text { he/she has } \\
\text { achieved? }\end{array}$ & \begin{tabular}{|l}
108 \\
Is he/she \\
fit and able \\
to work?
\end{tabular} & 109 \\
\hline & & & & Gen & hder & & $\begin{array}{l}\text { What is } \\
\text { his/her marital } \\
\text { status? } \\
0=\text { child or } \\
\text { not married } \\
1=\text { married } \\
\text { (nusband or first } \\
\text { wife) } \\
2=\text { married (2nd } \\
\text { wife) } \\
3=\text { married (3rd } \\
\text { or later wife) } \\
4=\text { widowed } \\
5=\text { separated or } \\
\text { divorced } \\
6=\text { other }\end{array}$ & $\begin{array}{l}\text { What is the } \\
\text { highest level of } \\
\text { education } \\
\text { he/she has } \\
\text { achieved? } \\
\\
0=\text { child below } \\
\text { school age } \\
1=\text { never attended } \\
\text { school } \\
2=\text { some primary } \\
\text { education } \\
3=\text { completed } \\
\text { primary education } \\
4=\text { some secondary } \\
\text { education } \\
5=\text { completed } \\
\text { secondary } \\
\text { education } \\
6=\text { any post- } \\
\text { secondary or } \\
\text { university education } \\
9=\text { does not know } \\
\end{array}$ & $\begin{array}{l}\text { Is he/she } \\
\text { fit and able } \\
\text { to work? } \\
0=\text { child } \\
\text { below working } \\
\text { age } \\
1=\text { Generally } \\
\text { good health: } \\
\text { does prod- } \\
\text { uctive work } \\
2=\text { Serious } \\
\text { disability or } \\
\text { sickness: } \\
\text { cannot do any } \\
\text { productive } \\
\text { work } \\
3=\text { Too old to } \\
\text { do any } \\
\text { productive } \\
\text { work. }\end{array}$ & $\begin{array}{l}\text { If he/she is } \\
\text { aged between } \\
7 \text { and } 18 \text { years } \\
\text { old: Did he/she } \\
\text { attend school } \\
\text { last week? } \\
1=\text { Did not attend } \\
\text { school } \\
2=\text { Attended } \\
\text { nursery or primary } \\
\text { school } \\
3=\text { Attended } \\
\text { secondary school } \\
4=\text { Attended post } \\
\text { secondary } \\
\text { education }\end{array}$ \\
\hline 1. & & $\square$ & $\square$ & $\square$ & $\square$ & 1 & 1 & 1 & 1 & 1 \\
\hline 2. & & $\square$ & $\square$ & $\square$ & $\square$ & 1 & 1 & 1 & 1 & 1 \\
\hline 3. & & $\square$ & $\square$ & $\square$ & $\square$ & 1 & 1 & 1 & 1 & 1 \\
\hline
\end{tabular}

Figures 1 and 2 show the differences in how paper-based and computer-assisted questionnaires look. On a mobile device, the design ensures that this question flow is followed, and the software dynamically pulls through the names entered in question 101, into questions 102-109.

Figure 2: Example household roster - mobile devices form
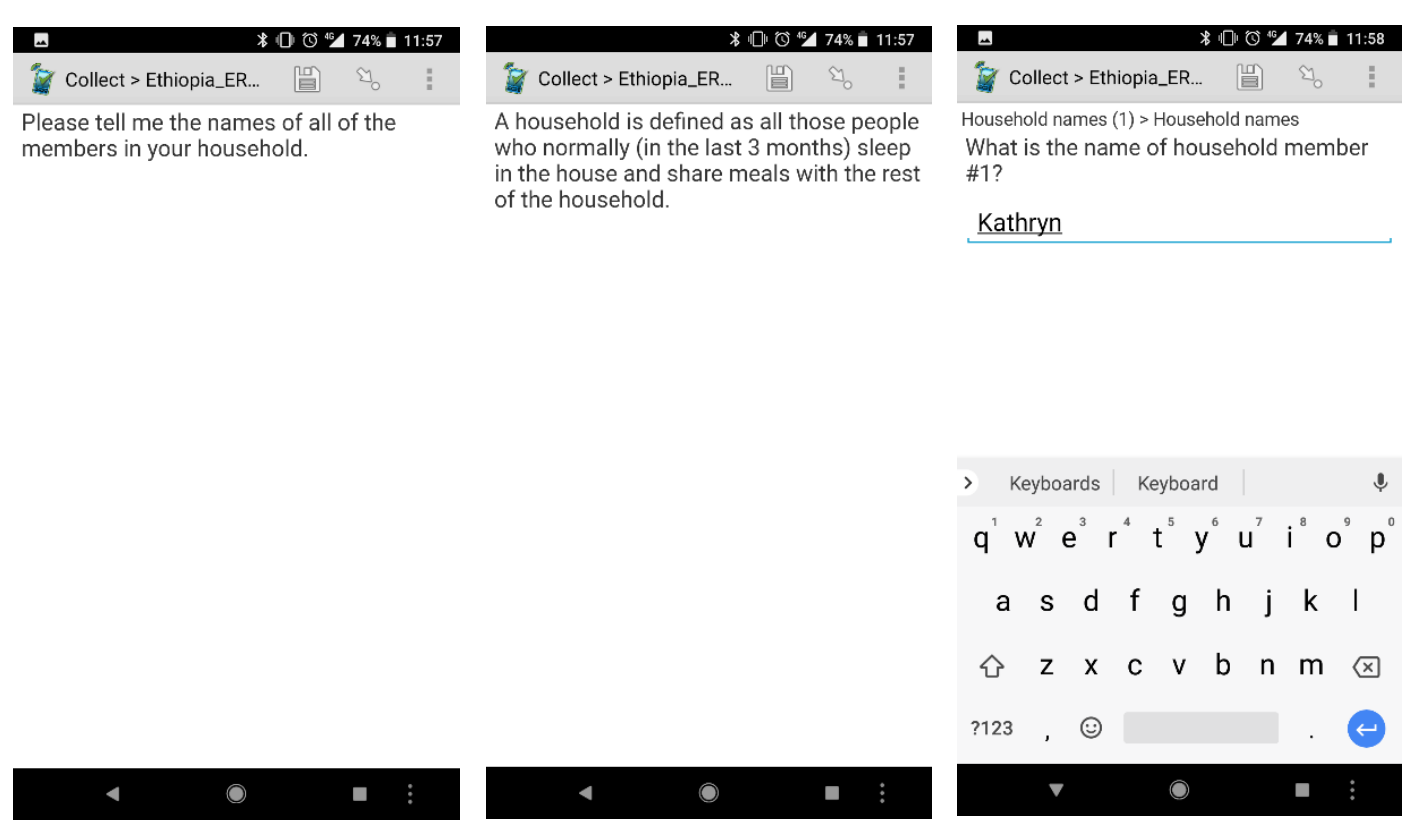


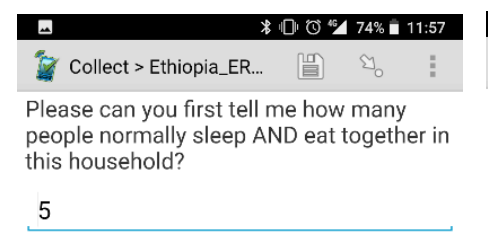

To further aid respondents and enumerators, the devices also display a summary table with the information entered, to minimize confusion in cases where there are many people within the household. This can be checked with the respondent and can easily be edited if required.

Examples of the SurveyCTO code that enables this flow is available in the appendix.

\section{CONSISTENCY CHECKS}

Another feature that digital data collection allows is on-the-spot consistency checks. This could be used through hard checks to reduce data-entry errors (such as typos or other types of mistakes), which purposely prevent moving on to the next step, or the survey from being completed, if there are predefined inconsistencies, and to flag potential inconsistencies for the enumerator's attention, or through soft checks, which may not be as rigid and allow movement to the next step, but still present an alert.

Overall, for each survey instrument, there could be the potential for a large number of such checks to be programmed. However, in order to not over-burden programmers and enumerators, and to avoid making the program too rigid, which could create challenges, checks should focus on critical variables for the future data analysis.

\section{HARD CHECKS - DOUBLE-ENTRY AND CONSTRAINTS}

Digital data collection allows for data to be entered as the interview is going on, reducing the chances of typos or other mistakes specific to data entry. Such mistakes are more likely to happen in continuous text or text variables, where enumerators do not choose from a list of options. To reduce the chances of typos even further, double-entry of a given survey question can easily be programmed. Hard checks are programmed so that in the case of mismatch between the two separate entries, enumerators have to go back and correct the data. An example of the SurveyCTO code is presented 
in the appendix on a continuous variable. The enumerator first asks 'How many rooms are there in your compound that are used for sleeping by your household members?' and enters the respondent's answer; the enumerator is then prompted to enter the value again, and the program checks for the two entries being the same.

Referring to the unique identifiers above, another way to reduce chances of mistakes when these are entered manually is to prompt the enumerator to enter the identifier at the very beginning and end of the survey. Ensuring the correct identifier is submitted is crucial for merging datasets, so if the enumerator enters two different identifiers, they would not be able to move forward. An example of the SurveyCTO code is presented in the appendix.

\section{HARD CHECKS - CALCULATION FUNCTIONS}

A clear advantage of using digital devices for data collection is the ability to instantly perform calculations. This is a useful feature when asking questions the answers to which need to add up to a certain number.

The calculation function was used in a data collection exercise investigating sources of income. Figure 4 shows the paper version of the questionnaire. Enumerators asked about the income received in the previous 12 months from a list of several income sources (questions $405 \mathrm{~A}$ to $405 \mathrm{~N}$ ). At the end, they had to add up all the values received and ask respondents to confirm if that represented the total amount received by the household in the last year. With the paper-based method, this process would involve an interruption in the interview process while the enumerator performed the calculation. However, using digital devices, the calculation (question 406) was conducted automatically. The SurveyCTO code for this is given in the appendix.

Figure 3: Sources of income calculation function - paper survey form

\begin{tabular}{|c|c|c|c|c|c|c|}
\hline & & 401 & 402 & 403 & 404 & 405 \\
\hline & & \multirow[b]{2}{*}{$\begin{array}{l}\text { Did any member } \\
\text { of your } \\
\text { household earn } \\
\text { any income from } \\
\text { this source } \\
\text { during the past } \\
12 \text { months? } \\
\begin{array}{l}1=Y e s \\
0=N o\end{array}\end{array}$} & \multirow[b]{2}{*}{$\begin{array}{l}\text { Did any member } \\
\text { of your } \\
\text { household earn } \\
\text { any income from } \\
\text { this source in the } \\
\text { year } 2014 ? \\
\begin{array}{l}1=\text { Yes } \\
0=N o\end{array}\end{array}$} & \multicolumn{3}{|l|}{ If 401 = Yes: } \\
\hline & & & & $\begin{array}{l}\text { In the last } 12 \\
\text { months, who } \\
\text { engaged in this } \\
\text { activity? } \\
\text { [list household } \\
\text { members] } \\
\text { Enter codes }\end{array}$ & $\begin{array}{l}\text { What was your } \\
\text { household's } \\
\text { income from } \\
\text { [Source] in the last } \\
\text { months? } \\
\text { JOD }\end{array}$ & $\begin{array}{l}\text { What was your } \\
\text { household's } \\
\text { income from } \\
\text { [Source] in the last } \\
12 \text { months? } \\
\text { JOD }\end{array}$ \\
\hline A & Cash for Work & & & & & \\
\hline B & $\begin{array}{l}\text { Payments from home } \\
\text { production sale (e.g. Sale } \\
\text { embroidery, carpet, food } \\
\text { preparation, handicrafts, } \\
\text { other) }\end{array}$ & & & & & \\
\hline C & $\ldots$ & T & 1 & & & | \\
\hline$N$ & Others & & & & & \\
\hline
\end{tabular}


Figure 4: Paper-based questionnaire - income questions

\begin{tabular}{|l|l|l|}
\hline 406 & \begin{tabular}{l} 
Would you consider [Make calculation] JOD to represent correctly the $\begin{array}{l}1=\mathrm{Yes} \\
\text { amount received by your household in the last year? }\end{array}$ \\
\hline 407
\end{tabular} & $\begin{array}{l}\text { If } 406=\mathrm{No} \\
\text { How much would you consider to be the amount received by your JOD } \\
\text { household in the last year? }\end{array}$ \\
\hline
\end{tabular}

The calculation feature was used for a weighting exercise during the Effectiveness Reviews conducted in Ethiopia, Somaliland and Nepal in 2015/2016. Respondents were asked to complete a 'budget allocation' exercise, designed to elicit their preferences over which dimensions of resilience they considered to be most important, by distributing a number of 'stones' across different dimensions to represent their priorities. Resilience was conceptualized using five dimensions, with each dimension represented by a picture, as shown in Figure 5. Respondents were asked to allocate a fixed number of stones to pictures that represented these dimensions, to express how important they considered each of these dimensions to be.

\section{Figure 5: Weighting worksheet from Ethiopia and Somaliland}

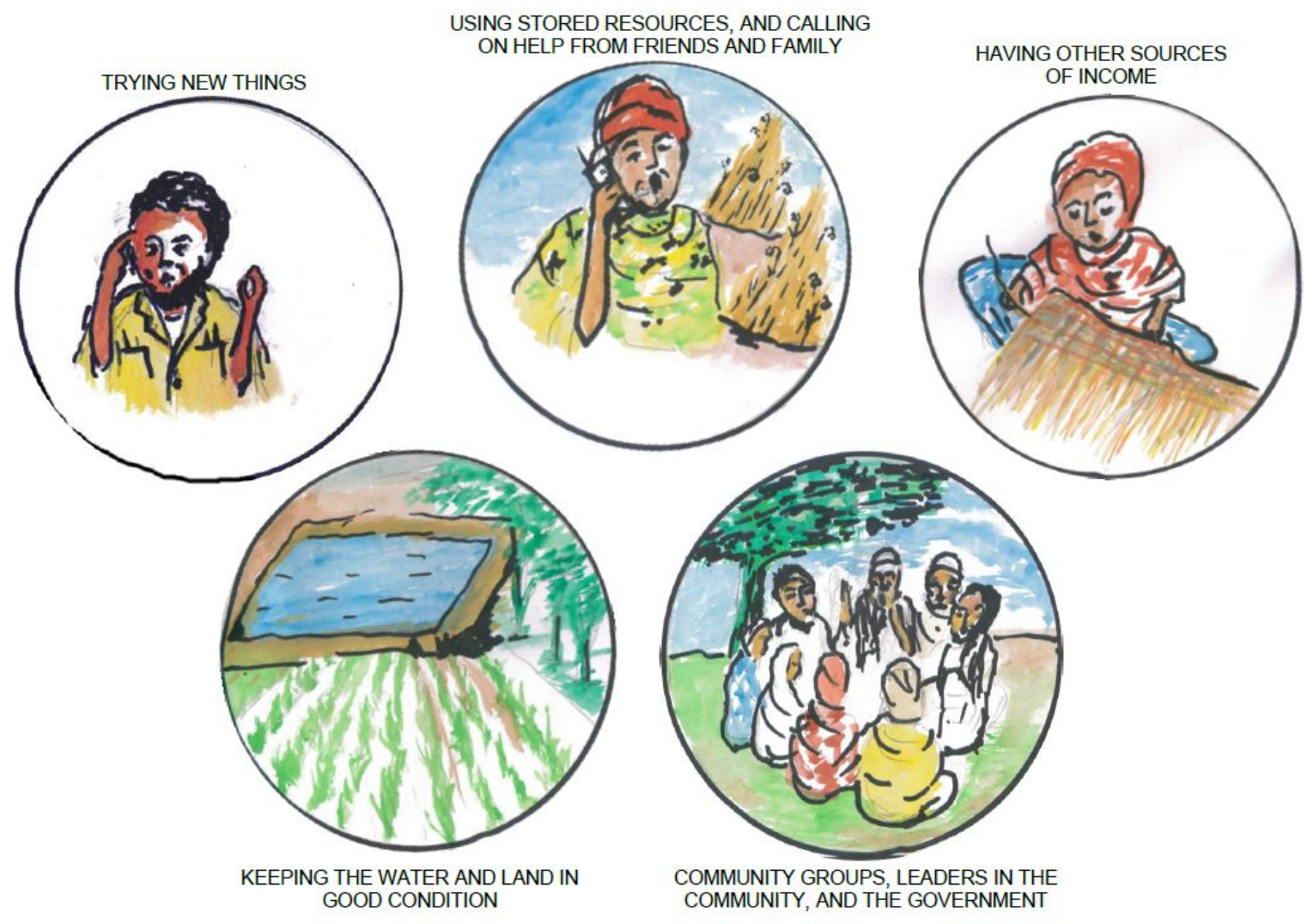

The total number of stones available to be allocated across the five dimensions was fixed, so respondents and enumerators were forced to allocate all the stones before being able to proceed with the interview. 
Figure 6: Example of weighting calculation - mobile devices form

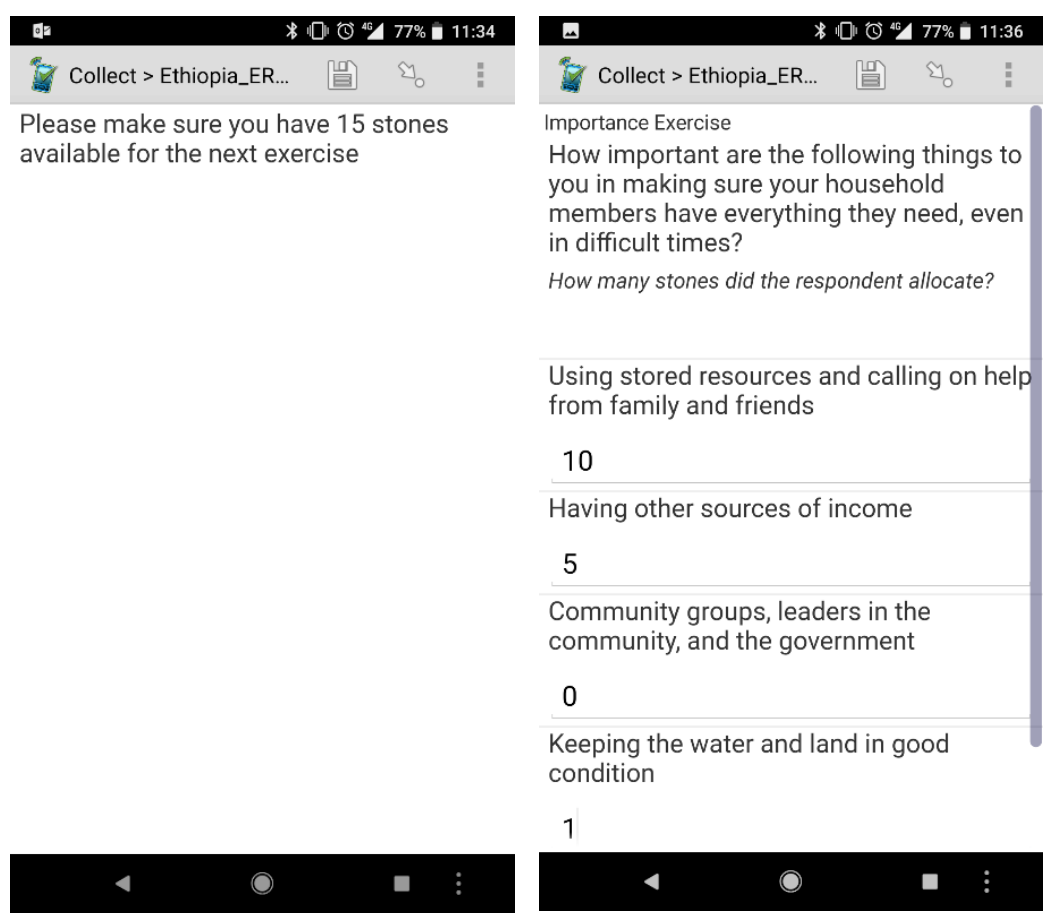

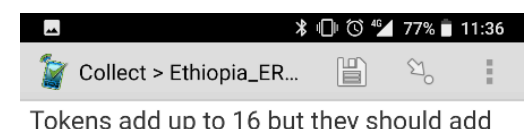

Tokens add up to 16 but they should add up to 15. PLEASE GO BACK AND CHANGE

The SurveyCTO code is available in the appendix.

\section{SOFT CHECKS - CALCULATION FUNCTIONS}

Soft checks can also be included in the survey to flag potential inconsistencies, which require further prompting of the respondent by the enumerator. When conducting an interview, enumerators have to not only create and maintain a good relationship with the respondent, but also make sure each question is well communicated and understood, and think critically about the consistencies of responses given across the survey to prompt the respondent as needed. Soft checks support the latter. They are particularly useful when some combinations of answers to key questions are unlikely, but not impossible, or when there is a need to allow flexibility. An example of each of these instances is given below.

A very basic use of the calculation function feature was used during a survey where the respondent was asked to estimate the proportion of income coming from different income channels. The question required the sum of the incomes from each channel to add up to $100 \%$ of the total income. A SurveyCTO code was developed to show to the enumerator an error message if the total value did not add up to $100 \%$. However, the code was deliberately designed to only flag the issue, allowing the enumerator to continue with the interview if they needed. 
Figure 7: Example income calculation - mobile devices form

Collect > ER Philippin...
In the last 12 months, what percentage of
your total household income came from:
Farming activities
70
Labour and salaries (e.g. empoloyment)
10
Business
0
Remittances
20
Other
5

4

○

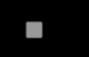

4

Another example relying on calculation functions is the combination of age and marital status in a household roster. The younger a household member is, the less likely this person is to be widowed. but there may be a very few cases of a household member being below 20 , and already a widow. To make sure the cases recorded as such reflect the actual situation and are not a typo in age or marital status for the specific household member, a soft check can be built into the program. Each time an enumerator enters 'widow' for the marital status of a household member below 20, a message popsup: 'Enumerator: you just filled that [Name of the household member] is a widow and is below 20; please check this information before moving forward.' The SurveyCTO code is presented in the appendix.

Many such combinations of variables are possible, and questionnaire programming will therefore focus on the most critical variables for future data analysis.

\section{RANDOMIZING SURVEY FEATURES}

Another function that is significantly useful in improving data quality and questionnaire design is the ability to introduce random variation in the survey features, which enables performing $A / B$ testing on questionnaire designs, testing the impact of one design approach versus another.

For example, Oxfam GB's Impact Evaluation team randomized two questionnaire modules on timeuse during an Effectiveness Review in Indonesia on a women's empowerment project. Comparing the results from this $A / B$ experiment provided valuable information on the strengths and weaknesses of the two designs. It provided evidence to enable striking a balance between accuracy and time required to collect the data. 
Findings suggest that while one version takes longer, on average, to administer, it is also more reliable in reducing enumerators' bias. Full findings, analysis and questionnaire design are reported in the following blog: Measuring time: Comparing questionnaire designs.

A similar approach was used as part of a larger multi-country field experiment on surveyor identity and response bias. We randomized the consent form at respondent level to suggest that the enumerator was conducting the survey either on behalf of Oxfam or a local independent survey company. While both were true, the experiment aimed to test whether individuals' responses were systematically influenced by the type of organization that respondents believed to be conducting the study. ${ }^{5}$ The analysis of the data is currently underway and will be shared soon. The SurveyCTO code is in the appendix.

\section{SURVEY PROGRESS MONITORING AND AUTOMATED QUALITY CHECKS}

A significant feature of digital data collection technologies is the ability to download and process the data instantly while the collection is still taking place. As we previously argued in Going Digital: Using and sharing real-time data during fieldwork, this has the potential to increase engagement and participation in surveyed communities. Additionally, we argue that this feature also has the potential to improve data quality by monitoring incoming data while data collection is still underway.

In close collaboration with the survey manager, this enables the identification of potential training weaknesses or misunderstanding, enumerators who need additional supervision, and data mistakes and inconsistencies that need correction through call back of respondents or second visits. These checks need to be focused in order for the survey manager to take action on them promptly, while data collection is still ongoing.

While each questionnaire has its own features, and each data collection exercises its own protocol, we provide here a general, but not exhaustive, list of some of the monitoring and automated quality checks we have implemented in the past that can be used in other surveys. There are different ways to do this, and an effective way is to develop a Stata dofile ${ }^{6}$ which automatically runs through the data and outputs descriptive statistics and observations that need further enquiry in a sharable format. The relevant (simple) Stata code examples are presented in the appendix. $^{7}$

There are many ways to write the code to perform the checks presented below and output the results. The output format and the communication flow with the survey team matter as much as performing the check itself.

Some of the monitoring checks include:

1. Checking the response rate and the number of completed interviews:

- by geographical area, to follow survey progress, which may help identifying areas where respondents are harder to interview than others, and get feedback on the reasons why;

- by enumerator, to identify enumerators who have more or less difficulty in conducting surveys;

- by treatment arms, to assess if there are significant differences between intervention and comparison groups due to survey implementation and/or availability or willingness of respondents to take part in the survey.

An example of Stata code for monitoring the number of completed surveys per enumerator and outputting this statistics in an Excel file (dofile 1, line 30 to 49) is presented in the appendix. 


\section{Checking the survey duration by enumerator}

Digital data collection allows for time stamps throughout the survey. This check can be performed for the whole survey duration or for a specific module of interest. Checking for differences in average survey duration per enumerator allows the flagging of enumerators who conduct interviews longer or shorter than the average. Both scenarios will require additional supervision from the survey manager to understand the drivers of this variation and take appropriate action.

An example of the Stata code is given in the appendix (dofile 1, line 50 to 112), in which we look at the average, minimum and maximum survey duration per enumerator, based on the variable survey duration created by the questionnaire program. The code also outputs the share of surveys that lasted less than 15 minutes (an arbitrary threshold that may be needed at the onset of the survey, when very few surveys were completed), less than half the median survey duration, or more than twice the median survey duration, by enumerator. An example of outputting the list of surveys that are particularly short and need more investigation is also given.

\section{Duplicates and matching of IDs}

Checking on a daily basis for duplicates in IDs as the data comes in allows for communication with the survey team and immediate correction of the mistakes. Similarly, in a setting where several surveys are matched and data collected simultaneously, checking for matching as the data comes in will allow for corrections.

An example of Stata code for a survey protocol in which up to two individual surveys were conducted per household survey are presented in the appendix (dofile2). The code identifies duplicate IDs in the household and individual surveys separately and outputs such cases in an Excel file for communication with the survey team. The code then checks for mismatches between the household survey and individual surveys, and outputs unmatchable IDs for further investigation.

Some of the quality checks include:

\section{Checking for the distribution of continuous variables}

Looking at the distribution of continuous variables gives valuable information, particularly at the start of the survey, as it can allow the person doing the remote monitoring to spot misunderstandings from specific team members, typos, or geographical specificities that require more investigation (for example a unit conversion factor being different from an area to another). As more data comes in, one can look at outliers based on mean and standard deviation of the distribution (particularly on the righthand-side of the distribution for positive continuous variables) and the concentration of those outliers per enumerator or per geographical area.

An example of Stata code is presented in the appendix (dofile 1, line 124 to 134). The code looks at the distribution of variables by tabulating them (required at the onset of a survey when very few observations are collected), identifies outliers, ${ }^{8}$ and looks at enumerators and geographical locations for which outlier observations are identified. The code then outputs the share of surveys with outlier value per enumerator (similar code can be written by geographical area), and outputs the pseudoanonymized data of specific observations that require more investigation and correction by the survey team.

\section{Checking for internal consistency}

Inconsistency, as mentioned above, is combinations of entries that are either impossible (but could not be programmed as hard checks in the survey programming) or possible, but very unlikely. This could be particularly important in cases where different questions about similar topics take place at 
different points in the questionnaire, where it is less easy for the enumerator to catch the inconsistency and probe further. For example, an early question asks about participation in a group, while later questions ask about knowledge of the existence of this group. Participants of the group should know of its existence. If this is not built into the questionnaire program as a hard check (or even a soft check), this could be monitored to flag the consistency in answers without having alerted respondents or enumerators at the time of submission. Another example could be the relationship between age and marital status mentioned above. If these are key variables for the analysis, monitoring the likelihood of such cases will ultimately enhance data quality ${ }^{9}$ through communication with the survey team.

An example of Stata code is given in the appendix (dofile 1, line 167 to 200). The code flags inconsistent observations (defined when two variables do not equate - the condition will be specific to the questionnaire in hand), then outputs the proportion of surveys with the inconsistency per enumerator and the pseudo-anonymized data of specific observations that require more investigation and correction by the survey team.

\section{Checking for variation of key variables by enumerator}

In a setting where several enumerators are surveying the same respondents, following the same protocol, once enough data has been collected there would be no reason to observe variation by enumerator if enumerators were conducting surveys in the exactly the same way. Enumerator training on survey tools and protocols is designed to build a common understanding of the survey instrument and common practices. Checking for the distribution of key variables per enumerator will allow checking for whether enumerators are administering the survey in the same way. ${ }^{10}$ This could add value for key variables, or gate questions, which answer conditions skipping an entire set of questions.

An example of Stata code is presented in the appendix (dofile 1, line 201 to 226). The code looks at the distribution of key sections being skipped by the enumerator; the code outputs summary statistics per enumerator: share of surveys in which a given section is skipped, average number of sections skipped (out of 2 sections in this example) and total number of surveys. Number of skips and survey duration - check 2 - will be correlated.

\section{CONCLUSION}

Adding quality checks into the survey design of digitally enabled data collection can significantly improve the quality of survey data collected. This has obvious positive implications for the validity of the study, and it also reduces the time and resources spent on data cleaning, which can instead be invested in other activities, such as feeding results back to the communities (see Going Digital: Using and sharing real-time data during fieldwork). 
Many of these quality checks depend on the survey supervisors having enough time, expertise and resources to follow up with enumerators and respondents, and invest time in the re-training of enumerators if required. The choice of which quality checks to perform depends on the purpose of the survey and should be tailored accordingly. This is why carefully thinking and planning at the survey design and planning stage is key to ensuring that the quality checks add value rather than create a burden on the respondent or the survey team. It is important to note that our aim is to work in partnership with the enumerators and researchers who form the survey team. Quality checks never replace human interaction, and any discrepancies are investigated as a team.

Using digital data collection technologies responsibly has the potential to increase data quality, even when resources are limited. We hope that, by making these simple examples available, other colleagues will build on it, unlocking greater potential for knowledge, learning and, ultimately, impact. 


\section{APPENDIX}

\section{PRE-RECORDED CONSENT FORM}

Adding the number of seconds the audio file lasted into the minimum seconds column enabled the use of the speed violations count function. When the audio file for the Hindi language was played for less than 282 seconds this would flag an error within the data export. In the example below, however, we also wanted to find out how long the recording had been played for - recognizing that there is a difference between whether it has been played for five seconds, versus 280 , for example. To calculate this, the use of 'calculate_here' was added with the calculation column showing the expression 'once(duration())'. This was added both before the consent question and after, with the calculation function then subtracting the before and start times '\$\{consent_end_secs\}-\$\{consent_start_secs\}' to get the total time the audio recording was played for. Colours shown in the table below as per SurveyCTO .xls forms.

\begin{tabular}{|c|c|c|c|c|c|}
\hline type & name & label:english & calculation & media:audio:hindi & minimum_seconds \\
\hline calculate_here & consent_start_secs & & once(duration()) & & \\
\hline $\begin{array}{l}\text { select_one } \\
\text { yesno }\end{array}$ & consent_india & $\begin{array}{l}\text { If you have no further } \\
\text { questions and would } \\
\text { like to participate in the } \\
\text { survey, I will record } \\
\text { your consent to } \\
\text { participate, and we will } \\
\text { start the survey. Would } \\
\text { you like to continue? }\end{array}$ & & Survey Intro Hindi.wav & 282 \\
\hline calculate_here & consent_end_secs & & once(duration()) & & \\
\hline $\begin{array}{l}\text { speed } \\
\text { violations } \\
\text { count }\end{array}$ & consent_violation & & & & \\
\hline calculate & consent time total & & $\begin{array}{l}\$\{\text { consent_end_secs }\}- \\
\$\{\text { consent_start secs }\}\end{array}$ & & \\
\hline
\end{tabular}




\section{PRELOADING AND FILTERING UNIQUE IDENTIFIERS}

Using the SurveyCTO search function under the appearance column, the lists of geographical identifiers (region, district, village) and household IDs to select from are pulled out from the preload file and attached to the form. Using the 'matches' feature of the search function, each list is filtered out based on the previous selection, so that the enumerator selects household ID among the list of household IDs of respondents from the region, district and village selected. The code allows for flexibility in case there is a need to conduct the survey in areas or households that were not pre-identified, through the 'other' options for district, village and household ID.

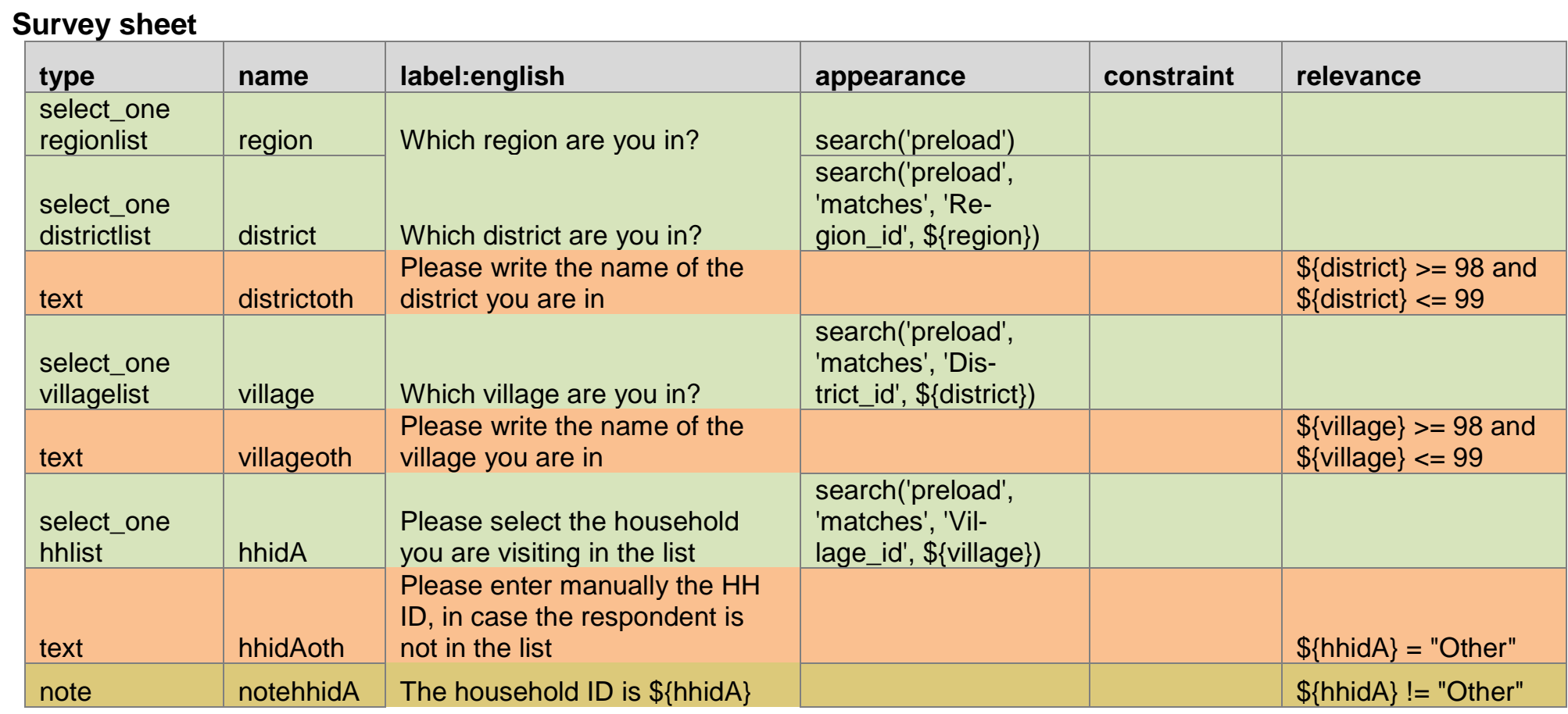




\section{Choices sheet}

\begin{tabular}{|l|l|l|}
\hline list_name & value & label:english \\
\hline regionlist & $\begin{array}{l}\text { Re- } \\
\text { gion_id }\end{array}$ & Region \\
districtlist & $\begin{array}{l}\text { Dis- } \\
\text { trict_id }\end{array}$ & District \\
\hline villagelist & $\begin{array}{l}\text { Vil- } \\
\text { lage_id }\end{array}$ & Village \\
\hline hhlist & HHID & Head_FM \\
\hline
\end{tabular}

\section{Preload file structure}

\begin{tabular}{|l|l|l|r|l|l|l|l|}
\hline Region & $\begin{array}{l}\text { Re- } \\
\text { gion_id }\end{array}$ & District & District_id & Village & Village_id & HHID & Head_FM \\
\hline Region 1 & 1 & BB & 1 & ZZZ & 1 & 1.01 .01 & Ayad (1.01.01) \\
\hline Region 1 & 1 & BB & 1 & ZZZ & 1 & Other & Other \\
\hline Region 1 & 1 & Other & 98 & Other & 98 & Other & Other \\
\hline Region 2 & 2 & AA & 2 & XXX & 2 & 2.02 .01 & Jenny (2.02.01) \\
\hline Region 2 & 2 & AA & 2 & XXX & 2 & Other & Other \\
\hline Region 2 & 2 & Other & 99 & Other & 99 & Other & Other \\
\hline
\end{tabular}

\section{GENERATING AD-HOC UNIQUE IDENTIFIERS}

Using household ID following the format 'Region ID. Village ID. Enumerator ID.Sampling order', region and village IDs are generated when the geographical information is selected in the list, and so is enumerator ID. The only information to enter manually is the sampling order, after having sampled households from hard-copy lists. The calculation function then generates the household ID by concatenating the region ID, village ID, enumerator ID and sampling order, ensuring that each of these is made of two digits. The note then displays the ID to the enumerator. 


\begin{tabular}{|c|c|c|c|c|c|c|}
\hline type & name & label:english & constraint & relevance & required & Calculation \\
\hline select_one region & region & $\begin{array}{l}\text { What is the name of the } \\
\text { region }\end{array}$ & & & yes & \\
\hline select_one village & village & $\begin{array}{l}\text { What is the name of the } \\
\text { village }\end{array}$ & & & yes & \\
\hline text & villageoth & $\begin{array}{l}\text { Please specify the name } \\
\text { of the village }\end{array}$ & & $\$\{$ village $\}=99$ & yes & \\
\hline select_one enumerator & enumerator & $\begin{array}{l}\text { Please select your } \\
\text { name: }\end{array}$ & & & yes & \\
\hline begin group & tracking & & & & & \\
\hline integer & sampling & $\begin{array}{l}\text { What is the sampling } \\
\text { order of this household? }\end{array}$ & $>0$ & & yes & \\
\hline calculate & hhid & & & & & $\begin{array}{l}\text { concat }(\text { if }(\$\{\text { region }\}<10, \text { concat }(0, \$\{\text { region }\}), \$\{\text { region }\}), " . ", \\
\text { if(\$\{village }<<10, \text { concat }(0, \$\{\text { village }\}), \$\{\text { village }\}), " . ", \\
\text { if( } \$\{\text { enumerator }\}<10, \text { concat }(0, \$\{\text { enumerator }\}), \$ \text { enumerator }\}), " . ", \\
\text { if } \$\{\text { sampling }\}<10, \text { concat }(0, \$\{\text { sampling }\}), \$\{\text { sampling }\}))\end{array}$ \\
\hline note & notehhid & $\begin{array}{l}\text { This respondent's ID is } \\
\$\{\text { hhid }\}\end{array}$ & & & & \\
\hline end group & tracking & & & & & \\
\hline
\end{tabular}

\section{HOUSEHOLD ROSTER INTERVIEW FLOW}

The household roster coding ensures that the workflow used on the paper version of the form can be continued in the digital format. The hhnumber field is limited to ensure that the answer is between 1 and 19, although this maximum figure can be changed depending on the context. This is done by using the constraint expression '. $<20$ and . $>0$ '. This number is then used to determine how many times the next set of questions is repeated in the roster. Firstly, the name of each household member is asked and the calculate row is used to remember the position that the names are given. Thus the question appears 'What is the name of household member \#1?'. The number increases up until the figure input into the hhnumber field is reached (up to a maximum of 19). 'Indexed-repeat' is used in the calculation fields for each household; this assigns the the number to the name so that the survey knows the order. The use of hhnumber in the choice_filter column creates the list of household names for enumerators to easily select who is the person being interviewed and who is the household head. This saves the names from being typed in for a second time. The next repeating section again uses hhnumber to repeat the set of questions based on the number in the household. However, using the indexed-repeat function as a calculation ensures that the right name from the household is pulled through. 
This avoids confusion, particularly with larger households where the order in which the names were given can be forgotten. There, when the question states, 'what is $\$$ \{namefromearlier\} gender?', it will change the $\$$ \{namefromearlier $\}$ into the name that was entered in the sequence earlier. Having 'table', in the appearance column, brings up a summary table at the bottom of the form page.

\begin{tabular}{|c|c|c|c|c|c|c|c|}
\hline type & name & label:english & constraint & Appearance & calculation & repeat_count & choice_filter \\
\hline integer & hhnumber & $\begin{array}{l}\text { Please can you first tell me } \\
\text { how many people normally } \\
\text { sleep together under the same } \\
\text { roof in this household for the } \\
\text { last } 12 \text { months? }\end{array}$ & $\begin{array}{l}<20 \text { and } \\
>0\end{array}$ & & & & \\
\hline begin repeat & names & Household names & & & & $\$\{$ hhnumber $\}$ & \\
\hline calculate & namenumber & & & & index() & & \\
\hline begin group & page3 & Household names & & & & & \\
\hline text & name & $\begin{array}{l}\text { What is the name of household } \\
\text { member } \# \$\{\text { namenumber }\} \text { ? }\end{array}$ & & & & & \\
\hline end group & page3 & Household names & & & & & \\
\hline end repeat & names & & & & & & \\
\hline calculate & name1 & & & & $\begin{array}{l}\text { indexed-repeat }(\$\{\text { name }\} \\
\$\{\text { names }\}, 1)\end{array}$ & & \\
\hline calculate & name2 & & & & $\begin{array}{l}\text { indexed-repeat(\$name\}, } \\
\$\{\text { names }\}, 2)\end{array}$ & & \\
\hline calculate & name3 & & & & $\begin{array}{l}\text { indexed-repeat }(\$\{\text { name }\} \\
\$\{\text { names }\}, 3)\end{array}$ & & \\
\hline calculate & name4 & & & & $\begin{array}{l}\text { indexed-repeat }(\$\{\text { name }\} \\
\$\{\text { names }\}, 4)\end{array}$ & & \\
\hline calculate & name5 & & & & $\begin{array}{l}\text { indexed-repeat }(\$\{\text { name }\} \\
\$\{\text { names }\}, 5)\end{array}$ & & \\
\hline calculate & name6 & & & & $\begin{array}{l}\text { indexed-repeat(\$nname\}, } \\
\$\{\text { names }\}, 6)\end{array}$ & & \\
\hline calculate & name7 & & & & $\begin{array}{l}\text { indexed-repeat(\$nname }\} \\
\$\{\text { names }\}, 7)\end{array}$ & & \\
\hline
\end{tabular}




\begin{tabular}{|c|c|c|c|c|c|c|}
\hline calculate & name8 & & & $\begin{array}{l}\text { indexed-repeat(\$\{name }\} \\
\$\{\text { names }\}, 8)\end{array}$ & & \\
\hline calculate & name9 & & & $\begin{array}{l}\text { indexed-repeat }(\$\{\text { name }\} \\
\$\{\text { names }\}, 9)\end{array}$ & & \\
\hline calculate & name10 & & & $\begin{array}{l}\text { indexed-repeat }(\$\{\text { name }\} \\
\$\{\text { names }\}, 10)\end{array}$ & & \\
\hline calculate & name11 & & & $\begin{array}{l}\text { indexed-repeat(\$\{name }\} \\
\$\{\text { names }\}, 11)\end{array}$ & & \\
\hline calculate & name12 & & & $\begin{array}{l}\text { indexed-repeat(\$nname }\} \\
\$\{\text { names }\}, 12)\end{array}$ & & \\
\hline calculate & name13 & & & $\begin{array}{l}\text { indexed-repeat(\$nname }\} \\
\$\{\text { names }\}, 13)\end{array}$ & & \\
\hline calculate & name14 & & & $\begin{array}{l}\text { indexed-repeat }(\$\{\text { name }\} \\
\$\{\text { names }\}, 14)\end{array}$ & & \\
\hline calculate & name15 & & & $\begin{array}{l}\text { indexed-repeat(\$nname }\} \\
\$\{\text { names }\}, 15)\end{array}$ & & \\
\hline calculate & name16 & & & $\begin{array}{l}\text { indexed-repeat( } \$\{\text { name }\} \\
\$\{\text { names }\}, 16)\end{array}$ & & \\
\hline calculate & name17 & & & $\begin{array}{l}\text { indexed-repeat }(\$\{\text { name }\} \\
\$\{\text { names }\}, 17)\end{array}$ & & \\
\hline calculate & name18 & & & $\begin{array}{l}\text { indexed-repeat }(\$\{\text { name }\} \\
\$\{\text { names }\}, 18)\end{array}$ & & \\
\hline calculate & name19 & & & $\begin{array}{l}\text { indexed-repeat }(\$\{\text { name }\} \\
\$\{\text { names }\}, 19)\end{array}$ & & \\
\hline begin group & page4 & Identifying household member & & & & \\
\hline $\begin{array}{l}\text { select_one } \\
\text { hhmember }\end{array}$ & interviewee & Identify the person interviewed & & & & $\$\{$ hhnumber $\}>=$ filter \\
\hline $\begin{array}{l}\text { select_one } \\
\text { hhmember }\end{array}$ & headhh & $\begin{array}{l}\text { Identify the head of the } \\
\text { household }\end{array}$ & & & & $\$\{$ hhnumber $\}>=$ filter \\
\hline end group & page4 & Identifying household member & & & & \\
\hline begin repeat & hhroster & Household roster & table & & $\$\{$ hhnumber $\}$ & \\
\hline calculate & namefromearlier & & & $\begin{array}{l}\text { indexed-repeat }(\$\{\text { name }\} \\
\$\{\text { names }\}, \text { index }())\end{array}$ & & \\
\hline begin group & page5 & $\$\{$ namefromearlier $\}$ details & & & & \\
\hline
\end{tabular}




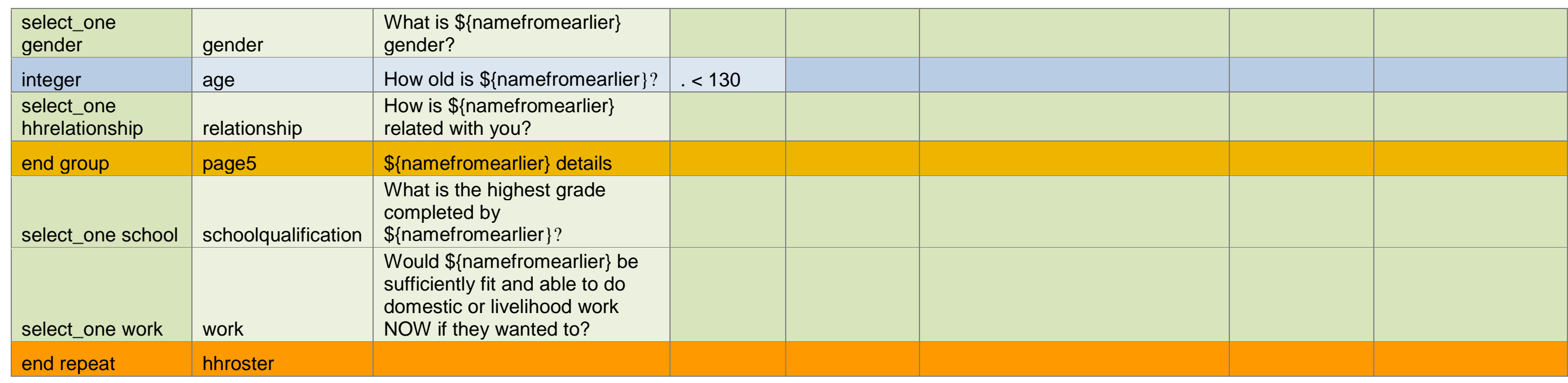

\section{HARD CHECKS - DOUBLE-ENTRY AND CONSTRAINTS}

Using the constraint function, the consistency of two entries of the same field is checked. In the case of the two entries not matching, a message is displayed 'The two entries do not match! Please go back, check, and make the necessary correction.' to the enumerator's attention.

\begin{tabular}{|c|c|c|c|c|c|}
\hline type & name & label:english & hint:english & constraint & Constraint message:english \\
\hline integer & huthouseroomsnow & $\begin{array}{l}\text { How many rooms are there in your } \\
\text { compound, which are used for } \\
\text { sleeping for your household } \\
\text { members? }\end{array}$ & $\begin{array}{l}\text { Do not include kitchen and } \\
\text { bathroom/toilet areas. }\end{array}$ &.$>=0$ and.$<=50$ & \\
\hline integer & huthouseroomsnow2 & 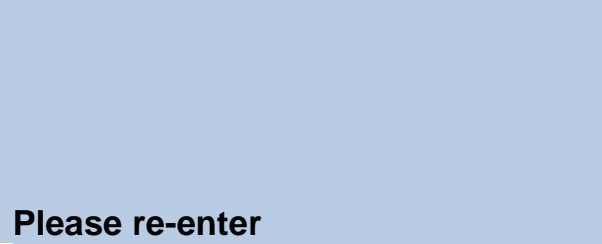 & $\begin{array}{l}\text { How many rooms are there in your } \\
\text { compound, which are used for } \\
\text { sleeping for your household } \\
\text { members? Do not include kitchen } \\
\text { and bathroom/toilet areas. }\end{array}$ & $\begin{array}{l}.= \\
\$\{\text { huthouseroomsnow\} }\end{array}$ & $\begin{array}{l}\text { The two entries do not match! } \\
\text { Please go back, check, and } \\
\text { make the necessary correction. }\end{array}$ \\
\hline
\end{tabular}


Similarly, a second entry of the survey unique identifier could be performed at the end of the survey, using the constraint function. If the two entries do not match, a message is displayed to the enumerator 'The Household ID does not match with the one entered at the beginning of the survey!' so that the enumerator can check on tracking tools and correct.

\begin{tabular}{|c|c|c|c|c|c|}
\hline type & name & label:english & hint:english & $\begin{array}{l}\text { con- } \\
\text { straint }\end{array}$ & constraint message:english \\
\hline text & hhid2 & $\begin{array}{l}\text { Enumerator please enter the household } \\
\text { ID again; kind reminder that this ID } \\
\text { starts by } \$\{\text { villenum }\} \text { : }\end{array}$ & $\begin{array}{l}\text { Reminder: the Household ID follows the format: "Village } \\
\text { ID.Enumerator ID.Date.Survey order" }\end{array}$ & $=\$\{$ hhid $\}$ & $\begin{array}{l}\text { The Household ID does not match with } \\
\text { the one entered at the beginning of the } \\
\text { survey! }\end{array}$ \\
\hline
\end{tabular}

\section{CALCULATION FUNCTIONS 1}

The calculation code here uses a repeating section to pull through a csv file that holds the income sources list. Using this csv format means that it is easier to simply change the options in the csv file from project to project rather than having to change the raw coding. The begin repeat row and calculate rows pull the csv income source information through in the right order to appear in the questions. This repeat and calculate is repeated again for the second set of repeat questions, named incomesource_repeat2, with the relevance ' $\$$ incomesource_selected2 $\}=1$ ' meaning only those who selected that they had earned income from any of the sources in the last 12 months. In this second repeated group, information about monthly and yearly income is obtained for each selected source. All the values are then summed up in

calculateincomeyeartot with the calculate function 'sum(\$\{incomeyear_\})'. The respondent is then asked to confirm if the total estimate is correct, and if not, to provide a more accurate estimate.

\begin{tabular}{|c|c|c|c|c|c|c|}
\hline type & name & label:English & constraint & Relevance & calculation & repeat_count \\
\hline note & noteincomesource & $\begin{array}{l}\text { Now I will ask you some } \\
\text { questions about sources } \\
\text { of income in which you } \\
\text { and other members of } \\
\text { your household have } \\
\text { engaged in, during the } \\
\text { past } 12 \text { months. }\end{array}$ & & & & \\
\hline $\begin{array}{l}\text { begin } \\
\text { repeat }\end{array}$ & incomesourcegroup & Source of income & & & & $\begin{array}{l}\text { int(pulldata('incomelist', } \\
\text { 'incomecount', } \\
\text { 'incomeid_key', '1')) }\end{array}$ \\
\hline
\end{tabular}




\begin{tabular}{|c|c|c|c|c|c|}
\hline calculate & incomesource_id1 & & & index() & \\
\hline calculate & incomesource_name1 & & & $\begin{array}{l}\text { pulldata('incomelist', } \\
\text { 'incomename:english', } \\
\text { 'incomeid_key', } \\
\text { \$\{incomesource_id1\}) }\end{array}$ & \\
\hline $\begin{array}{l}\text { begin } \\
\text { group }\end{array}$ & page8 & Source of income & & & \\
\hline $\begin{array}{l}\text { select_one } \\
\text { yesno }\end{array}$ & incomesource_selected_ & $\begin{array}{l}\text { In the last } 12 \text { months, did } \\
\text { you or anyone in your } \\
\text { household earn any } \\
\text { income from } \\
\$\{\text { incomesource_name } 1\} ?\end{array}$ & & & \\
\hline $\begin{array}{l}\text { select_one } \\
\text { yndk }\end{array}$ & incomesource_selected2014_ & $\begin{array}{l}\text { In } 2014, \text { did you or } \\
\text { anyone in your household } \\
\text { earn any income from } \\
\$\{\text { incomesource_name } 1\} ?\end{array}$ & & & \\
\hline end group & page8 & & & & \\
\hline end repeat & incomesourcegroup & & & & \\
\hline $\begin{array}{l}\text { begin } \\
\text { repeat }\end{array}$ & incomesource_repeat2 & Crop production & & & $\begin{array}{l}\text { int(pulldata('incomelist', } \\
\text { 'incomecount', } \\
\text { 'incomeid_key', '1')) }\end{array}$ \\
\hline calculate & incomesource_id2 & & & index() & \\
\hline calculate & incomesource_name2 & & & $\begin{array}{l}\text { indexed- } \\
\text { repeat(\$\{incomesource_name1\}, } \\
\$\{\text { incomesourcegroup\}, } \\
\$\{\text { incomesource_id } 2\})\end{array}$ & \\
\hline calculate & incomesource_selected2 & & & $\begin{array}{l}\text { indexed- } \\
\text { repeat }(\$\{\text { incomesource_selected_\}, } \\
\$\{\text { incomesourcegroup }\} \\
\$\{\text { incomesource_id } 2\})\end{array}$ & \\
\hline $\begin{array}{l}\text { begin } \\
\text { group }\end{array}$ & page8a & $\$\{$ incomesource_name 2$\}$ & $\$\{$ incomesource_selected 2$\}=1$ & & \\
\hline
\end{tabular}




\begin{tabular}{|c|c|c|c|c|}
\hline integer & incomemonth_ & $\begin{array}{l}\text { What was the total } \\
\text { household income from } \\
\text { \$incomesource_name2\} } \\
\text { in the LAST MONTH? }\end{array}$ &.$>=0$ & \\
\hline integer & incomeyear_ & $\begin{array}{l}\text { What was the total } \\
\text { household income from } \\
\text { \$\{incomesource_name2\} } \\
\text { in the LAST } 12 \\
\text { MONTHS? }\end{array}$ &.$>=0$ & \\
\hline end group & page8a & & & \\
\hline calculate & calculateincomeyeartot & & & sum(\$\{incomeyear_\}) \\
\hline $\begin{array}{l}\text { select_one } \\
\text { yesno }\end{array}$ & incomeyearconfirm & $\begin{array}{l}\text { Would you consider JOD } \\
\$\{\text { calculateincomeyeartot }\} \\
\text { to correctly represent the } \\
\text { total amount earned by } \\
\text { your household in the last } \\
\text { year? }\end{array}$ & & \\
\hline integer & incomeyearrevised & $\begin{array}{l}\text { How much would you } \\
\text { consider to be the amount } \\
\text { received by your } \\
\text { household in the last } \\
\text { year? }\end{array}$ &.$>=0$ & \\
\hline
\end{tabular}

\section{CALCULATION FUNCTIONS 2}

Using the SurveyCTO, calculations and relevance functions were added into the design to prevent the enumerator from continuing if the total did not equal to the desired number. This was done by adding a weighting calculation that added the five dimensions together and then a required note field stating 'Tokens add up to \$\{weighting_calculation\} but they should add up to 15 . PLEASE GO BACK AND CHANGE'. This note included relevance, which ensured that it only appeared when the total was not 15 (expressed as ' $\$$ \{weighting_calculation\} != 15' in the code). The question was also required, meaning that enumerators had to go back and correct the answers before being able to proceed with the interview. 


\begin{tabular}{|c|c|c|c|c|}
\hline type & name & label & constraint & constraint message \\
\hline begin group & weighting & Importance Exercise & & \\
\hline note & weighting_exercise & How many tokens did the respondent allocate? & & \\
\hline integer & $\begin{array}{l}\text { contingency_re- } \\
\text { sources }\end{array}$ & $\begin{array}{l}\text { Using stored resources and calling on help from family and } \\
\text { friends }\end{array}$ & & \\
\hline integer & livelihood_viability & Having other sources of income & & \\
\hline integer & social_institutional & $\begin{array}{l}\text { Community groups, leaders in the community, and the gov- } \\
\text { ernment }\end{array}$ & & \\
\hline integer & $\begin{array}{l}\text { integrity_environ- } \\
\text { ment }\end{array}$ & Keeping the water and land in good condition & & \\
\hline integer & innovation_potential & Trying new things & $\begin{array}{l}\$\{\text { contingency_resources\}+\$\{livelihood_via- } \\
\text { bility\} } \\
+\$\{\text { social_institutional\} }+\$\{\text { integrity_environ- } \\
\text { ment\} } \\
+\$\{\text { innovation_potential\} }=15\end{array}$ & $\begin{array}{l}\text { Tokens do not add up to } \\
\text { 15. Please go back and } \\
\text { change. }\end{array}$ \\
\hline end group & weighting & & & \\
\hline
\end{tabular}

\section{CALCULATION FUNCTIONS 3}

The code below demonstrates a soft check where enumerators could proceed with the survey even if the calculation did not add up to $100 \%$. To do this, the calculation field added together all the integer answers using the code shown below. A note field was then added using the relevance, ' $\$\{$ percentageincometotal $\} !=100$ ', which told the note field to only show if the answer did not add up to $100 \%$. This note field remained an optional field in this instance and therefore enabled the enumerator to continue. This could easily be changed into a hard check by marking the field as required and thereby ensuring the enumerator went back to correct the answer. 


\begin{tabular}{|c|c|c|c|c|}
\hline Type & Name & label & Relevance & Calculation \\
\hline begin group & page 9 & Percentage of income & & \\
\hline note & percentageincome & $\begin{array}{l}\text { In the last } 12 \text { months, what percentage of your } \\
\text { total household income came from: }\end{array}$ & & \\
\hline integer & share_farming & Farming activities & & \\
\hline integer & share_labour & Labour and salaries (e.g. employment) & & \\
\hline integer & share_business & Business & & \\
\hline integer & share_remitt & Remittances & & \\
\hline integer & share_otherproduct & Other & & \\
\hline end group & page9 & & & \\
\hline calculate & percentageincometotal & & & $\begin{array}{l}\text { (\$\{share_farming }\}+\$\{\text { share_labour }\}+\$\{\text { share_busi- } \\
\text { ness }\}+\$\{\text { share_remitt }\}+\$\{\text { share_otherproduct }\})\end{array}$ \\
\hline note & $\begin{array}{l}\text { percentageincometotal- } \\
\text { note }\end{array}$ & $\begin{array}{l}\text { Your total household income does not equal } \\
100 \% \text { - PLEASE GO BACK AND CHANGE }\end{array}$ & $\begin{array}{l}\$\{\text { percentageincometotal }\} != \\
100\end{array}$ & \\
\hline
\end{tabular}

\section{CALCULATION FUNCTION - SOFT CHECK}

Using the calculation and relevance functions, each time a household member is identified with characteristics that may need further probing (being below 20 and a widow, in this example), a message is displayed: 'Enumerator: you just filled that "Household member's name" is a widow and is below 20; please check this information before moving forward.' Using a note rather than a constraint makes it a soft check: if this information is correct, the enumerator does not make any change and moves forward with the interview. The code below also calculates the total number of such cases in the household roster (the variable youngwidow_flag), for monitoring purposes. 


\begin{tabular}{|c|c|c|c|c|c|c|}
\hline type & name & label:English & appearance & relevance & calculation & repeat_count \\
\hline begin repeat & hhroster & Household roster & & & & $\$\{$ hhnumber $\}$ \\
\hline calculate & namefromearlier & & & & $\begin{array}{l}\text { indexed-repeat }(\$\{\text { name }\} \\
\$\{\text { names }\} \text {, index }())\end{array}$ & \\
\hline begin group & rostergenage & $\$\{$ namefromearlier $\}$ details & field-list & & & \\
\hline select_one gender & gender & What is $\$\{$ namefromearlier\}'s gender? & & & & \\
\hline integer & age & How old is $\$\{$ namefromearlier\}? & & & & \\
\hline select_one marital & marital & $\begin{array}{l}\text { What is } \$ \text { \{namefromearlier\}'s marital } \\
\text { status? }\end{array}$ & & & & \\
\hline end group & rostergenage & & field-list & & & \\
\hline calculate & youngwidow & A widow is below 20 & & & $\begin{array}{l}\text { if }(\$\{\text { marital }\}=3 \text { and } \$\{\text { age }\}< \\
20,1,0)\end{array}$ & \\
\hline note & youngwidownote & $\begin{array}{l}\text { Enumerator: you just filled that } \\
\$\{\text { namefromearlier\} is a widow and is } \\
\text { below 20; please check this information } \\
\text { before moving forward. }\end{array}$ & & $\begin{array}{l}\$\{\text { youngwidow }\}= \\
1\end{array}$ & & \\
\hline begin group & rosterschoolwork & $\$\{$ namefromearlier $\}$ details & field-list & & & \\
\hline select_one highested & highested & $\begin{array}{l}\text { What is the highest level of education } \\
\$\{\text { namefromearlier\} has achieved? }\end{array}$ & & & & \\
\hline select_one fitwork & fitwork & Is $\$\{$ namefromearlier $\}$ able to work? & & & & \\
\hline $\begin{array}{l}\text { select_one } \\
\text { attendschool }\end{array}$ & attendschool & $\begin{array}{l}\text { Did } \$\{\text { namefromearlier }\} \text { attend school in } \\
\text { the last week of last term? }\end{array}$ & & & & \\
\hline end group & rosterschoolwork & $\$\{$ namefromearlier $\}$ details & field-list & & & \\
\hline end repeat & hhroster & & & & & \\
\hline calculate & youngwidow_flag & $\begin{array}{l}\text { Young widow - Number of cases in the } \\
\text { roster }\end{array}$ & & & $\operatorname{sum}(\$\{$ youngwidow $\})$ & \\
\hline
\end{tabular}




\section{RANDOMIZING QUESTIONS}

Below is the code used to perform the $A / B$ testing. This is implemented by using the relevance ' $\$\{$ randomtimeAB $<<=0.50$ ' on the two question modules with a calculation 'once(random())' to ensure that respondents were randomly assigned to either group A or group B.

\begin{tabular}{|c|c|c|c|c|}
\hline type & Name & label:English & relevance & calculation \\
\hline calculate_here & startconsent & & & once(duration()) \\
\hline calculate & random $A B$ & & & once(random()) \\
\hline $\begin{array}{l}\text { select_one } \\
\text { yesnoconsent }\end{array}$ & consent $A$ & $\begin{array}{l}\text { Good morning/afternoon. My name is } \ldots \text { I am conducting a survey on behalf of OXFAM. OXFAM } \\
\text { is an international organization working to develop long-lasting solutions against poverty and promote } \\
\text { campaigns for social change. } \\
\text { OXFAM is carrying out this survey to evaluate a former OXFAM project and to help understand about } \\
\text { the lives of women in this community. } \\
\text { I would like to request your participation in a short interview about women's empowerment. } \\
\text { Please be aware that no special support will come to your household as a result of your responses to } \\
\text { the questions. Any information you provide will be used for research and evaluation purposes. Data will } \\
\text { not be shared in a way where you or any other household member could be identified. } \\
\text { If you have concerns after the survey, you can withdraw your response at a later date by contacting the } \\
\text { offices of OXFAM. }\end{array}$ & $\begin{array}{l}\$\{\text { randomAB }\}<= \\
0.50\end{array}$ & \\
\hline
\end{tabular}




\begin{tabular}{|c|c|c|c|}
\hline $\begin{array}{l}\text { select_one } \\
\text { yesnoconsent }\end{array}$ & consentB & $\begin{array}{l}\text { Good morning/afternoon. My name is } \\
\text { ration with other local partner organizations (LET, ATFD, AFTURD). OXFAM is an international organi- } \\
\text { zation working to develop long-lasting solutions against poverty and promote campaigns for social } \\
\text { change. } \\
\text { OXFAM is carrying out this survey to evaluate a former OXFAM project and to help understand about } \\
\text { the lives of women in this community. } \\
\text { I would like to request your participation in a short interview about women's empowerment. } \\
\text { Please be aware that no special support will come to your household as a result of your responses to } \\
\text { the questions. Any information you provide will be used for research and evaluation purposes. Data will } \\
\text { not be shared in a way where you or any other household member could be identified. } \\
\text { If you have concerns after the survey, you can withdraw your response at a later date by contacting the } \\
\text { offices of OXFAM. } \\
\text { Are you willing for us to spend approximately one hour with you carrying out an interview? }\end{array}$ & $\$\{$ random $A B\}>0.50$ \\
\hline
\end{tabular}




\section{AUTOMATED QUALITY CHECKS WITH STATA}

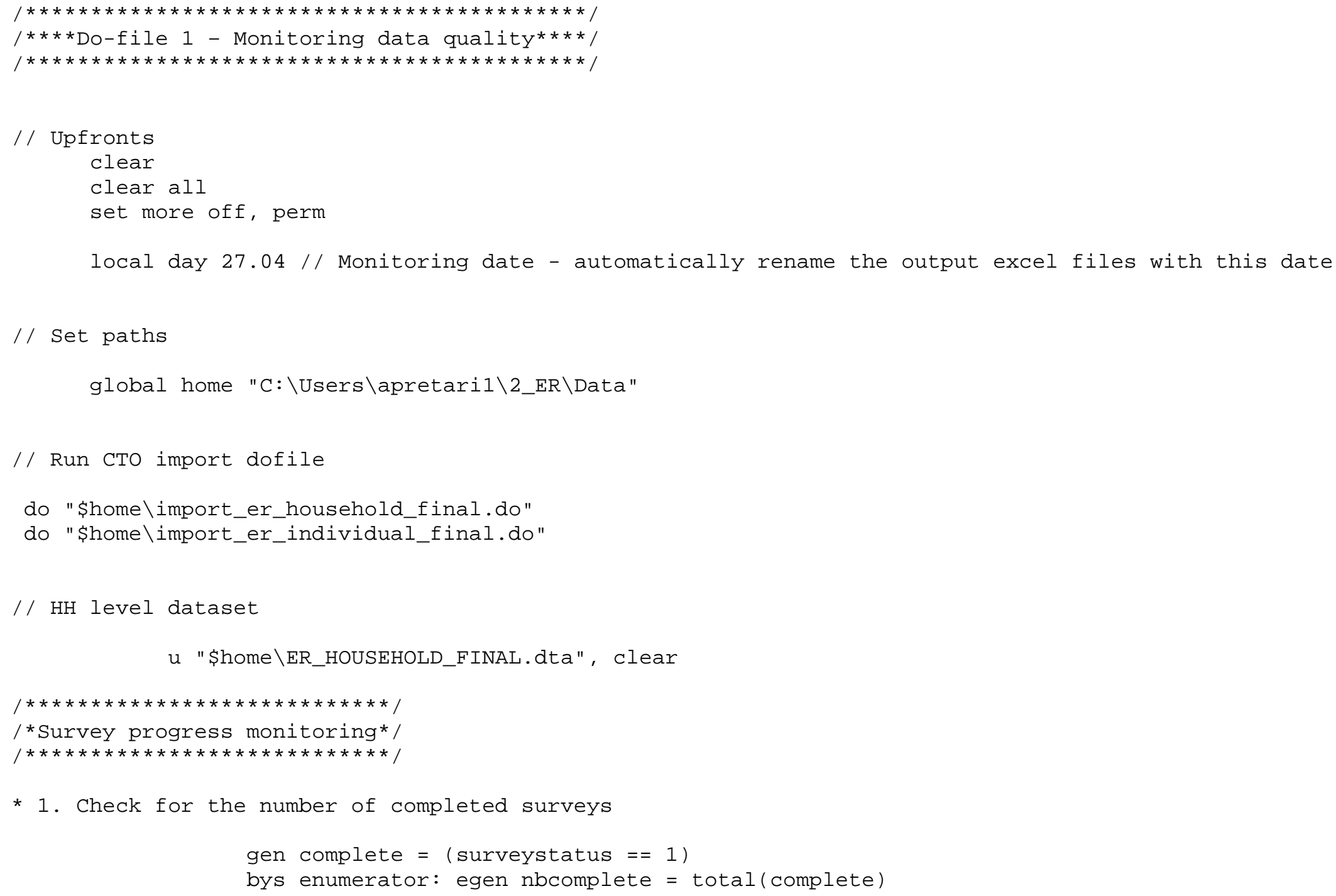


// Outputting summary statistics by enumerator

preserve

keep enumerator nbcomplete

duplicates drop

tion") sheetreplace

export excel using "\$home\monitoring_'day'.xlsx", firstrow(varl) sheet("HH survey - comple-

restore

* 2. Check of the survey duration by enumerator

// Turning surveyduration in minutes

destring surveyduration, replace

summ surveyduration

gen surveyduration_min = surveyduration / 60

summ surveyduration_min

summ surveyduration_min, d

gen hhsurveybelow15 = (surveyduration_min $<=15$ ) // shorter than 15 minutes - if willing to set an arbitrary threshold, at onset of the survey

gen hhsurveyshort $=$ (surveyduration_min $<=' r(p 50) ' / 2$ ) // shorter than half the median duration

gen hhsurveylong $=$ (surveyduration_min $>={ }^{\prime} r(p 50)^{\prime *} 2$ \& surveyduration_min ! = .) // longer than twice the median duration

// Looking at the data by enumerator

bys enumerator: summ surveyduration_min

label var surveyduration_min "Survey duration (minutes)"

// creating summary statistics by enumerator

by enumerator: egen surveydur_mean = mean (surveyduration_min)

label var surveydur_mean "Average survey duration" 
by enumerator: egen surveydur_min = min(surveyduration_min) label var surveydur min "Minimum survey duration"

by enumerator: egen surveydur_max $=\max$ (surveyduration_min)

label var surveydur_max "Maximum survey duration"

by enumerator: egen surveydur_nb = count (surveyduration_min)

label var surveydur_nb "Number of completed surveys"

* Share of surveys by enumerator that are:

* below $15 \mathrm{~min}$

* shorter than half the median duration

* longer than twice the median duration

foreach $x$ in below15 short long \{

by enumerator: egen hhsurvey ' $x$ '_mean = mean (hhsurvey ' $x^{\prime}$ )

label var hhsurvey ' $x$ '_mean "Share of ' $x$ ' surveys"

// Outputting summary statistics by enumerator

preserve

keep enumerator surveydur_* hhsurvey* mean

duplicates drop

sheetreplace

export excel using "\$home\monitoring_`day'.xlsx", firstrow(varl) sheet("HH survey - duration")

\section{restore}

// Listing the surveys that are too short and needs investigation / call back

preserve

keep if hhsurveyshort $==1$

keep hhid starttime submissiondate endtime datetimeend surveyduration_min

sheetreplace

export excel using "\$home\monitoring_'day'.xlsx", firstrow(varl) sheet("HH survey - too short!")

restore 


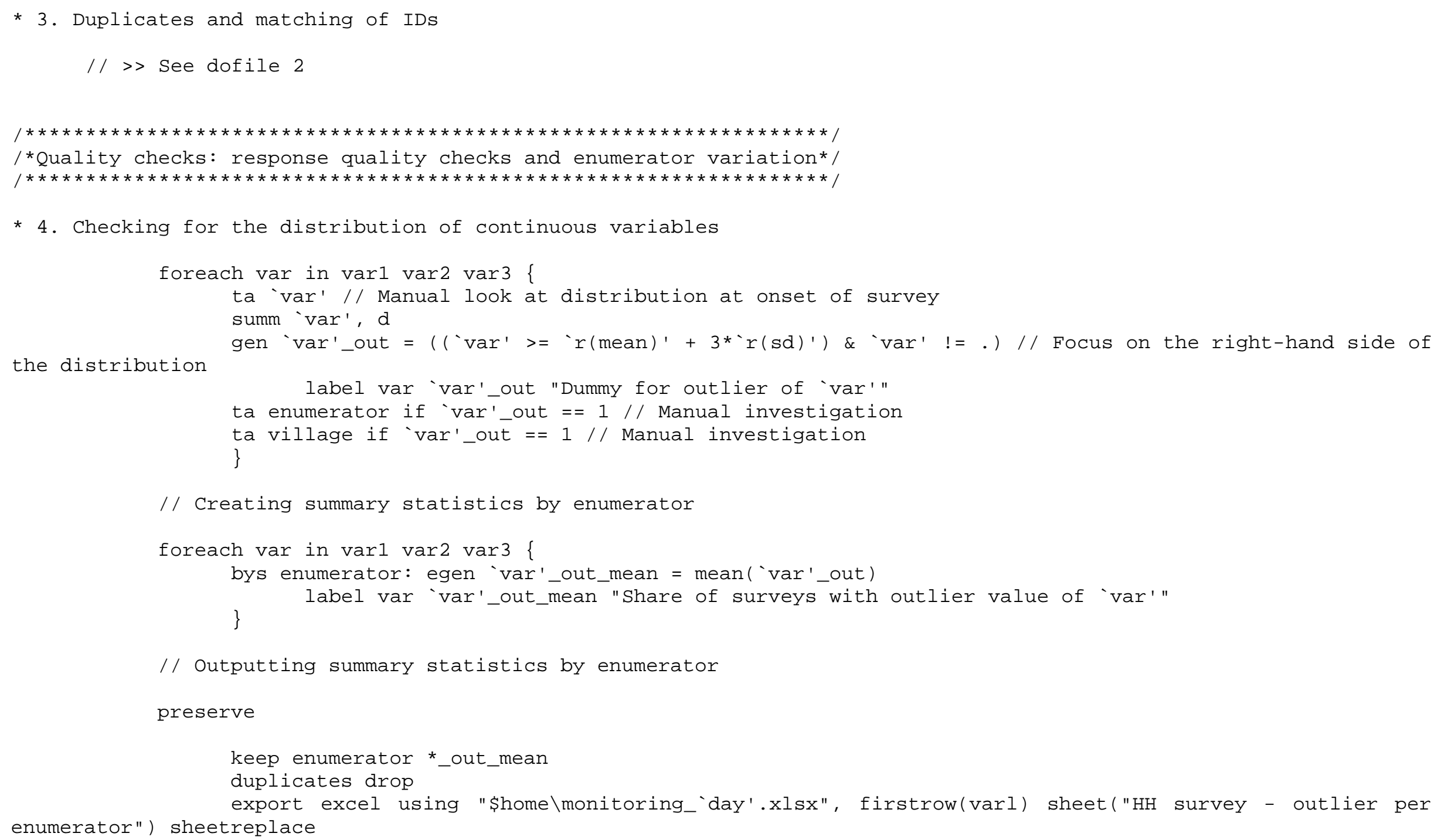




\section{preserve}

keep if (var1_out $==1 \mid$ var2_out $==1 \mid$ var3_out $==1$ )

keep enumerator hhid var1 var1_out var2 var2_out var3 var3_out

duplicates drop

tions") sheetreplace

export excel using "\$home\monitoring_'day'.xlsx", firstrow(varl) sheet("HH survey - outlier correc-

restore

* 5. Checking for internal consistency

gen inconsistency $=(\operatorname{var} 1 !=\operatorname{var} 2)$ if complete $==1$

ta enumerator if inconsistency $==1 / /$ Looking manually

// Creating summary statistics by enumerator

bys enumerator: egen inconsistency_mean = mean (inconsistency)

label var inconsistency_mean "Share of surveys with inconsistency"

// Outputting summary statistics by enumerator

preserve

keep enumerator inconsistency_mean nbcomplete

duplicates drop

sheetreplace

export excel using "\$home\monitoring_'day'.xlsx", firstrow(varl) sheet("HH survey - inconsistency")

\section{restore}

// Listing the surveys that need correction

preserve

keep if inconsistency $==1$ 
keep enumerator hhid var1 var2

duplicates drop

export excel using "\$home\monitoring_'day'.xlsx", firstrow(varl) sheet("HH survey - correction")

sheetreplace

restore

* 6. Checking for variation by enumerator

gen skipcrop $=($ crop $!=1)$ if complete $==1$

gen skiplivestock = (anylivestock $!=1$ ) if complete $==1$

gen nbskip = skipcrop + skiplivestock

// creating summary statistics by enumerator

foreach var in skipcrop skiplivestock \{

bys enumerator: egen 'var' mean = mean ('var')

\} label var 'var'_mean "Share of surveys for which 'var' == 1"

bys enumerator: egen nbskip_mean = mean(nbskip)

label var nbskip_mean "Average number of sections being skipped"

// Outputting summary statistics by enumerator

preserve

keep enumerator *skip*_mean nbcomplete

duplicates drop

export excel using "\$home\monitoring_'day'.xlsx", firstrow(varl) sheet("HH survey - skip") sheet-

replace

restore 


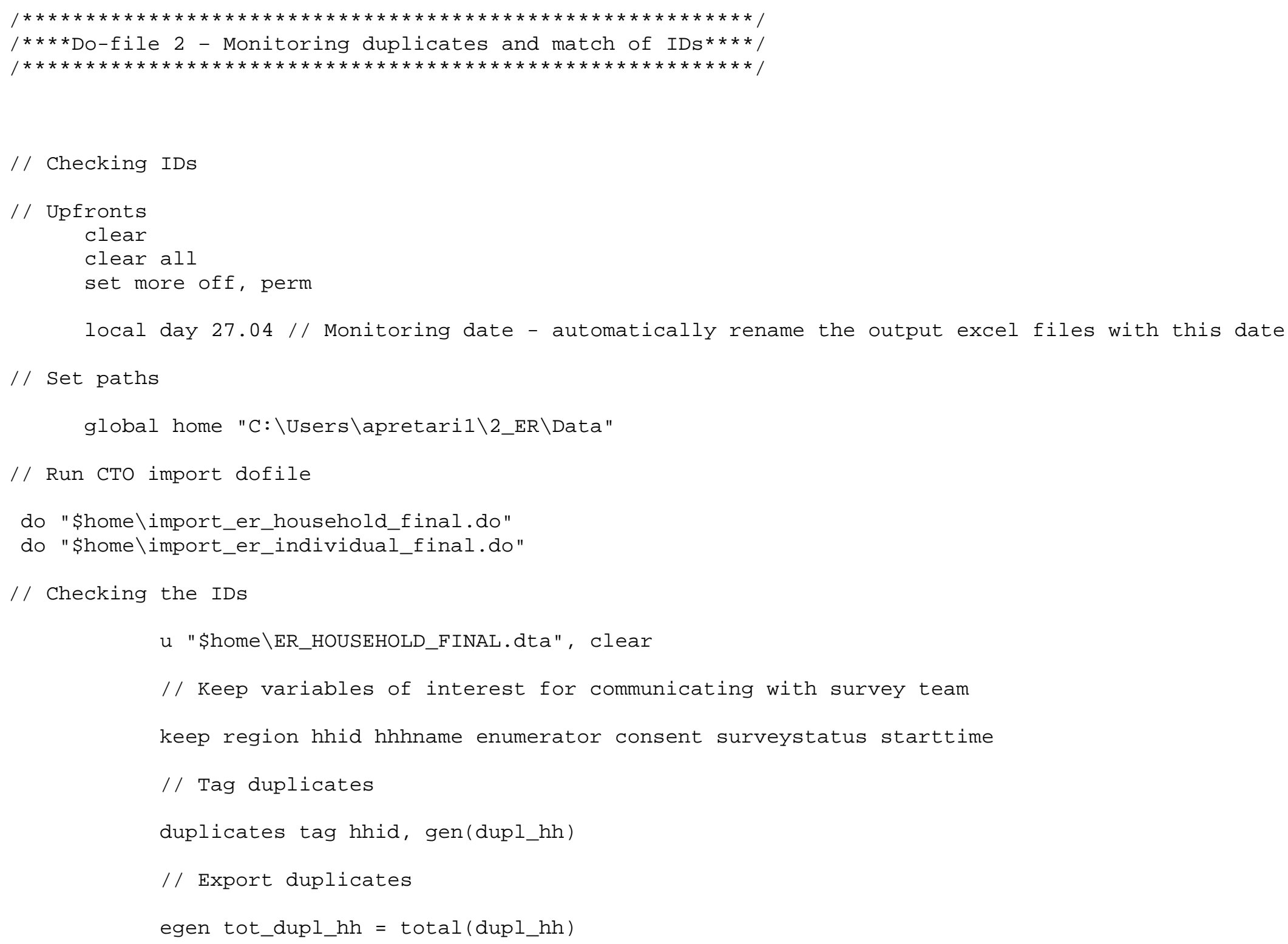


if tot_dupl_hh $>=1\{$

preserve

keep if dupl_hh $>=1$

keep hhid hhhname

sort hhid

export excel using "\$home\monitoring_`day'.xlsx", firstrow(var) sheet("HH duplicates") sheet-

replace

restore

sort hhid

// Add suffix to variables

ren **_hh

ren hhid_hh hhid

// Save file for merging

tempfile check

save 'check'

u "\$home\ER_INDIVIDUAL_FINAL.dta", clear

// Keep variables of interest for communicating with survey team

keep region hhid indid respname enumerator consent surveystatus starttime

// Tag duplicates

duplicates tag indid, gen(dup_indid)

egen tot_dup_indid = total(dup_indid)

if tot_dup_indid $>=1$ 


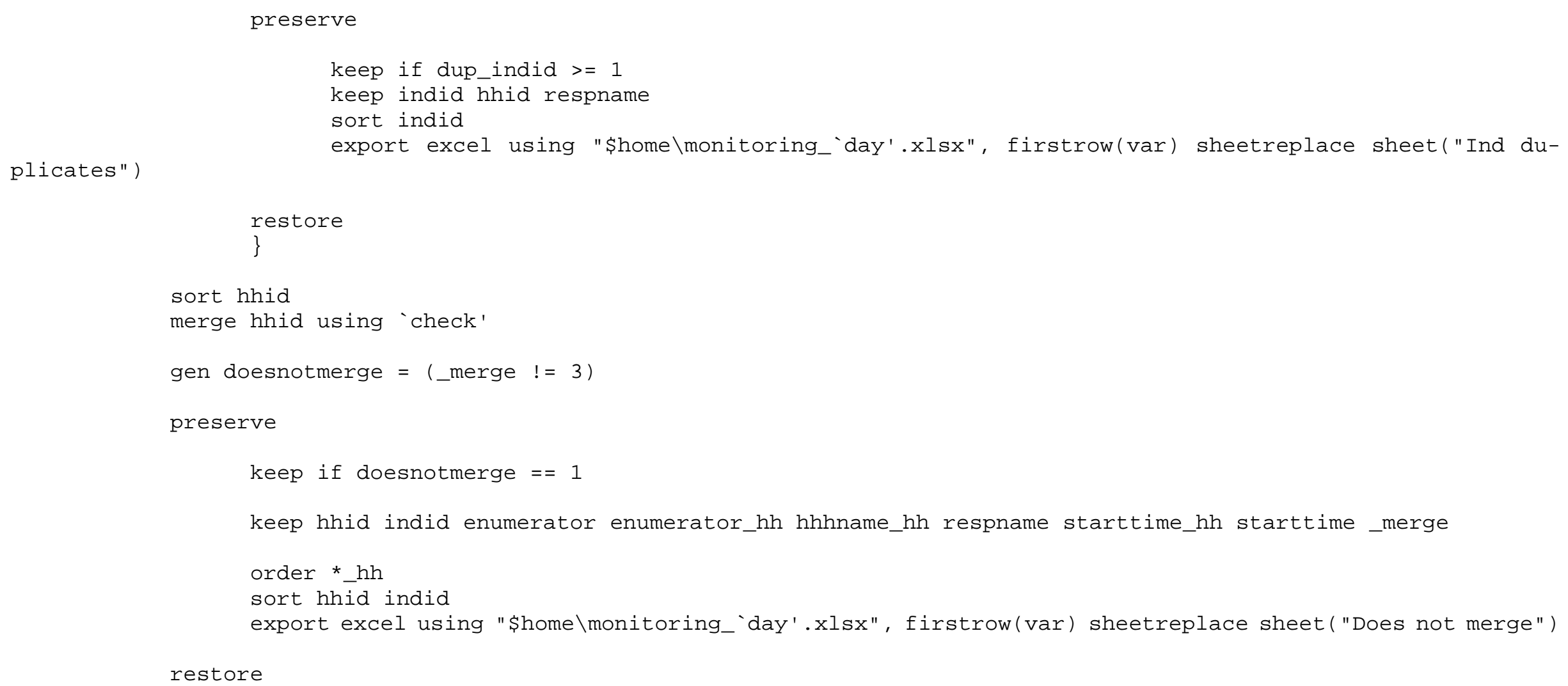




\section{ACKNOWLEDGEMENTS}

We would like to thank Jonathan Lain, Andrew Anduko (former Oxfam Impact Evaluation Advisers) and Kristen McCollum, former Impact Evaluation Intern, who contributed by developing and shaping some of the features reported in this paper. Thanks also to the consultants we have used as well as Oxfam Canada who managed the data collection activities where many of these quality checks were initially piloted. Finally, our thanks to the SurveyCTO team, who supported us in the creation of some of these survey features.

\section{RELEVANT LINKS}

E. Tomkys and S. Lombardini (2015). Going Digital: Using digital technology to conduct Oxfam's Effectiveness Reviews. Oxford: Oxfam GB. http://policy-practice.oxfam.org.uk/publications/goingdigital-using-digital-technology-to-conduct-oxfams-effectiveness-reviews$\underline{578816}$

S. Lombardini and E. Tomkys Valteri (2017). Going Digital: Using and sharing real-time data during fieldwork. Oxford: Oxfam GB. https://policy-practice.oxfam.org.uk/publications/goingdigital-using-and-sharing-real-time-data-during-fieldwork-620432

Oxfam International (2015). Oxfam Responsible Program Data Policy. Oxfam International. https://policy-practice.oxfam.org.uk/publications/oxfam-responsible-program-data-policy$\underline{575950}$

S. Lombardini (2017). Measuring time: Comparing questionnaire design. [blog] https://viewsvoices.oxfam.org.uk/methodology/2017/01/real-geek-measuring-time-comparing-questionnaire-designs

E. Tomkys and L. Eldon (2016). Mobile Survey Toolkit. Oxford: Oxfam GB. https://policypractice.oxfam.org.uk/publications/mobile-survey-toolkit-617456

World Bank IE unit Wiki: https://dimewiki.worldbank.org/wiki/Main Page

J-Pal online resources: https://www.povertyactionlab.org/research-resources/measurementand-data-collection 


\section{NOTES}

1 See the World Bank Impact Evaluation Unit wiki, for example https://dimewiki.worldbank.org/wiki/Main Page which presents guidelines on survey practices, data collection management and monitoring, which are complementary to this publication.

2 Code will be in SurveyCTO and Stata as these are the software packages used by the team. Of course, these solutions can be used by other software e.g. R

3 Oxfam's Responsible Program Data Policy

4 Provided listing data can be sent to the server through an internet connection, the SurveyCTO 'Dataset' function allows automation of the sampling process and the generation of a preload file while the listing households is conducted.

5 Due to ethical concerns, and specifically to ensure informed consent and avoid any deception of respondents, the experiment implemented the following measures. First, the consent form explicitly stated that data would be used for research and evaluation purposes, and would not be shared in a way that any household could be identified. Second, when the field supervisors contacted village authorities to arrange permission to enter each village, they were trained to mention the names of all organizations involved. Third, if a respondent asked for more information on the organization(s) conducting the survey, enumerators were carefully trained to truthfully mention all organizations involved.

6 Or any statistical software that enables coding and performing pre-defined analysis. SurveyCTO Data Explorer is another way to run some of these checks, which does not require access to the whole dataset, but only to the key fields on which to run the checks. This can be particularly useful in dealing with different skill sets within the team, and/or with different team members having access to different information to meet confidentiality requirements.

7 For more on this, see the J-Pal's High Frequency Checks Guide (forthcoming): https://www.povertyactionlab.org/researchresources/measurement-and-data-collection

8 Any value higher than the sum of the mean and 3 standard deviations.

9 The SurveyCTO code presented in the appendix creates a variable flagging the number of household members recorded as widows and below 20 in the household roster; this variable is created in the questionnaire program to be used for monitoring.

10 Testing for statistical differences is doable but requires enough data to be collected before such tests can be performed. 

This case study was written by Emily Tomkys Valteri, Alexia Pretari and Simone Lombardini. It is part of a series of papers and reports written to inform public debate on development and humanitarian policy issues.

For further information on the issues raised in this paper please email etomkysvalteri@oxfam.org.uk.

This publication is copyright but the text may be used free of charge for the purposes of advocacy, campaigning, education, and research, provided that the source is acknowledged in full. The copyright holder requests that all such use be registered with them for impact assessment purposes. For copying in any other circumstances, or for re-use in other publications, or for translation or adaptation, permission must be secured and a fee may be charged. Email policyandpractice@oxfam.org.uk.

The information in this publication is correct at the time of going to press.

Published by Oxfam GB under ISBN 978-1-78748-307-1 in July 2018.

DOI: $10.21201 / 2018.3071$

Oxfam GB, Oxfam House, John Smith Drive, Cowley, Oxford, OX4 2JY, UK.

\section{OXFAM}

Oxfam is an international confederation of 20 organizations networked together in more than 90 countries, as part of a global movement for change, to build a future free from the injustice of poverty. Please write to any of the agencies for further information, or visit www.oxfam.org. 